\title{
Nudge, Boost, or Design? Limitations of behaviorally informed policy under social interaction
}

\author{
Samuli Reijula ${ }^{1 *}$, Jaakko Kuorikoski², Timo Ehrig ${ }^{3}$, Konstantinos Katsikopoulos ${ }^{4}$, Shyam \\ Sunder 5
}

\begin{abstract}
Nudge and boost are two competing approaches to applying the psychology of reasoning and decision making to improve policy. Whereas nudges rely on manipulation of choice architecture to steer people towards better choices, the objective of boosts is to develop good decision-making competences. Proponents of both approaches claim capacity to enhance social welfare through better individual decisions. We suggest that such efforts should involve a more careful analysis of how individual and social welfare are related in the policy context. First, individual rationality is not always sufficient or necessary for improving collective outcomes. Second, collective outcomes of complex social interactions among individuals are largely ignored by the focus of both nudge and boost on individual decisions. We suggest that the design of mechanisms and social norms can sometimes lead to better collective outcomes than nudge and boost, and present conditions under which the three approaches (nudge, boost, and design) can be expected to enhance social welfare.
\end{abstract}

JEL Classification: D78; D04; D91; D71; Z13

\section{Keywords}

nudge - boost - social welfare - mechanism design — social norm

1 University of Helsinki

${ }^{2}$ University of Tampere

${ }^{3}$ Max Planck Institute for Mathematics in the Sciences; University of Southern Denmark

${ }^{4}$ Max Planck Institute for Human Development; University of Southampton

${ }^{5}$ Yale School of Management

*Corresponding author: samuli.reijula@iki.fi

\section{Introduction: Behavioral science tools for improving welfare}

Recent decades have seen new proposals for using knowledge from psychology as input to policy. Much of this "behaviorally informed policy" has been aimed at improving personal decisions of individuals, implicitly assuming that more effective pursuit of individual goals also yields better consequences for society. This approach has also been applied to improving the well-being of people in situations where they need to coordinate their behavior, for example, in jointly managing resources (Hukkinen, 2016). Such problems cannot be reduced to the individual level, nor should they be considered on a par with statewide macroeconomic problems. We refer to these problems as belonging to the meso level.

Although the behavioral sciences can inform policy design in numerous ways, and also coercive forms of paternalism and regulation can benefit from behavioral insights, we focus on interventions that do not impose new regulations on behavior or significantly change people's monetary incentives. Such soft interventions attempt to influence behavior by changing cognitive and affective aspects of the situation, people's motivation, or their decision competences. They try to alter choices without constraining the opportunity sets of the decision makers.

The most prominent kinds of soft interventions are nudge and boost (Bond, 2009). Nudges were first introduced by Thaler and Sunstein $(2003,2008)$, and although there is considerable disagreement about what exactly constitutes a nudge intervention, nudges are soft interventions that improve people's welfare by manipulating the choice architecture of a situation in a way that helps to eliminate or mitigate a decisional inadequacy or a psychological bias. By using easily reversible means, a nudge should influence the nudgee's behavior towards a choice that he/she would ultimately be happy with (see Sunstein, 2015; Hertwig and Grüne-Yanoff, 2017).

Whereas nudging builds on the heuristics-and-biases research program in the psychology of decision making (Kahneman, Slovic, and Tversky 1982; Kahneman and Tversky, 2000), boosts originate in the fast-and-frugal-heuristics tradition (Gigerenzer 2007; Gigerenzer, Hertwig, and Pachur, 2011). Unlike nudges, boosts do not target immediate individual behaviors, but instead, they aim at building new decision competences or fostering existing ones (Hertwig and Grüne-Yanoff, 2017). Proponents of the boost program hold that people can make good, even ideal, decisions as long as 
they are educated to choose the appropriate rule of thumb for the situation or once they possess the competences for dealing with the relevant risks, probabilities, and statistics (Katsikopoulos, 2014; Gigerenzer, 2015).

Although there is a lively debate around the ethics of nudges, there has been less systematic discussion on the effectiveness and scope of different kinds of behavioral policy interventions. Johnson et al. (2012) discuss factors involved in designing choice architectures, and Bhargava and Loewenstein (2015) raise worries about the effectiveness of nudge interventions in contrast to more traditional policy tools. Also Chetty (2015) brings up some issues discussed in our paper, and Nagatsu (2015) provides an insightful discussion of the ethics of social nudges. To our knowledge, the only papers explicitly comparing nudge and boost interventions are GrüneYanoff and Hertwig (2016) and Hertwig and Grüne-Yanoff (2017). None of the articles above address the central topic of our paper: limitations of the individualistic behavioral policy interventions in situations involving social interaction between agents.

We argue that soft interventions targeting individual decision-making cannot simply be assumed to lead to improved social welfare at the meso level, because individual rationality is not always sufficient, or necessary, for social welfare. The systemic (sometimes unintended) consequences of interventions, and the mapping from individual to social welfare, i.e. the social welfare function, must be explicitly considered. We suggest conditions under which nudge, boost, and interventions on social interactions (mechanism and norm design) improve social welfare in meso problems.

\section{From individual rationality to social welfare?}

Although nudge and boost interventions differ in the means used, they share a methodological background in psychological decision-making research, and both aim to improve welfare by steering people towards more rational choices. The examples presented in Thaler and Sunstein (2008) refer to a mixture of individual and social problems but, in the end, offer solutions only for individual problems where the definition of improvement is uncontested, such as eating healthier or earning a higher return on financial investments ${ }^{1}$. Gigerenzer (2007) suggested educational interventions for boosting a patient's, doctor's or policy maker's understanding of the results of a medical test and their ability to decide accordingly ${ }^{2}$. While these interventions could scale up to the societal level (Gigerenzer and Muir Gray, 2011), they, too, start by pursuing individual improvement.

\footnotetext{
1 Thaler and Sunstein (2003) includes a brief discussion of the role of cost-benefit analysis in choosing between nudges. In Thaler and Sunstein (2008, ch. 3), the authors consider social nudges, but they only discuss social influence as a means for influencing individual decisions, not the complications that social interaction raises for the prediction and evaluation of outcomes.

${ }^{2}$ For examples of boosts, see Hertwig and Grüne-Yanoff (2017).
}

In many important policy problems, however, an assumption that improving individual decisions automatically leads to enhanced social welfare suggests a too simple picture of the situation. Irrespective of one's particular account of social welfare, it is well established that in a variety of economic and social phenomena, the rational pursuit of individual goals does not yield improved collective outcomes.

Consider the simple example of a public goods dilemma, such as whether to pay the fare for using public transportation. Although everyone benefits from the availability of a public good, each agent is better off free riding on others' contributions. Low fines combined with a low probability of apprehension render ticketless travel individually advantageous. Nudging individuals towards rationality (e.g., devising better ways of detecting undercover inspectors) would obviously put some change in their pockets but it would be a shortsighted gain leading ultimately to higher costs, congestion, discomfort, and travel time. Boosting people could mean improving their understanding of the game-theoretic aspects of the problem, with often similar consequences. So making individual decisions more rational does not necessarily lead to a desired collective outcome.

The unresolved disconnect between individual and social welfare is generally present in instances of the tragedy of the commons. Individual users of shared but slow-to-replenish resources, such as fisheries and forests, have an incentive to maximize their respective shares, depleting the resource to the eventual detriment of all. Indeed, virtually all kinds of fisheries as well as forests in large parts of the planet have been depleted rapidly over the past century (United Nations Food and Agriculture Organization 2014). However, as above, it is not clear what individual decision competency is found wanting.

Furthermore, defining the social welfare function for a policy problem is often normatively and politically problematic. Consider the well-known example of a successful nudge: the increase in pensions saving achieved by simply changing the default employee option. Yet it is not the case that increased saving is always macroeconomically beneficial. Even if the individuals targeted would save more if they were able to rationally optimize their consumption over their lifetime, it still does not necessarily follow that the whole society would be better off. Even prima facie straightforward cases of soft interventions can give rise to difficult problems regarding the relationships between individual and social welfare.

Where does the easy assimilation of individual rationality and social welfare come from? A common argument in the late 20th century was that market failures are a result of biased individual behavior, and if individuals would only be rational, markets would be efficient (Camerer, 1992). Yet, theoretical work in economics suggests that individual rationality is not always sufficient for social welfare. For example, in markets where disagreement and speculation play a role, speculation can be individually rational and still have a seriously negative impact on social welfare (Ben-Porath and Heifetz, 2011; 
Simsek, 2013).

The insufficiency of individual rationality for social welfare does not rule out individual rationality being a necessary condition for social welfare. However, the findings of Becker (1962), Smith (1962), and Gode and Sunder (1993) show that even when populated with less than rational agents, some markets can approximate the predictions of competitive equilibria. These results establish that individual rationality is not always needed for market efficiency.

The lesson to be drawn from this section is that the link between individual rationality and social welfare is very much determined by the structure of the institutions involved in the problem at hand. Only with knowledge of this structure can we meaningfully talk about the meso-level success of nudge and boost.

\section{Designing social interaction}

If the relationship between individual rationality and social welfare is more complicated than pure sufficiency or necessity, it may be worthwhile to approach the problem of improving social welfare by looking at the social institutions themselves. Mechanism (or market) design is a well-known class of interventions at the institutional level. Mechanism design need not involve changes in monetary incentives. Consider, for example, the entry-level labor market of doctors (i.e., residents) in the United States. Before the establishment of a clearinghouse mechanism (in 1952, revised in 1995) for matching residents and hospitals, the strategic behavior of both doctors and hospitals had led to inefficient practices that none of the parties were happy with (Roth 1984, 2008). Hospitals competed for good residents, and despite the uncertainty about their skills, students were often hired several years before graduation. Students suffered as well, as they had to make their acceptance decisions without the chance to compare competing offers.

The clearinghouse mechanism replaced the individual negotiations between residents and hospitals with both sides submitting a rank-ordered list of their preferences, after which a centralized algorithm would produce a matched list. As Roth (1984) has shown, the algorithm is stable in the sense that it never leaves a resident-hospital pair unmatched if the two would have mutually preferred to be matched together instead of being part of a different pair. The mechanism was received well by medical students and hospitals and it resulted in high participation rates.

The original labor market unraveled because the market players responded strategically to the actions of others. The solution was to set up a voluntary institution with a set of rules that most participants recognized would leave everybody, themselves included, better off. In its attempt to get participants to reveal their true preferences, this kind of institutional design may appear to be similar to nudge. But it is fundamentally different. The designed rules of the game are systemic, transparent, apply to all, and are targeted explicitly to reach particular collective outcomes.
Could mechanism design solve the problems involved in applying nudge and boost to the problems discussed above? On the face of it, the answer seems to be yes. In the case of overfishing, formation of secondary markets for fishing quotas or seafaring rights could provide incentives for reducing the catch so that those with the best possibilities for exiting the market would do so and those most dependent on the activity would not endure prohibitive personal and monetary costs ${ }^{3}$.

Another way of intervening on social structure is to modify the social norms governing the problematic practice (Cialdini et al., 1990). As an example, consider the recent work of Cristina Bicchieri and her collaborators (Bicchieri, 2006, 2016, see also Mackie, 1996), who have shown how intervening on social norms can be used to improve collective outcomes. Their central premise is that instead of arising from unconditional preferences, much of our behavior is based on conditional preferences: people participate in socially advantageous institutions at their own cost only if they believe that (i) others participate in the same behavior and (ii) others also expect everyone to participate.

For example, consider the case of Muslim women wearing a veil (Bicchieri, 2006, pp. 14-15). Even though a large part of the population might individually regard wearing a veil as burdensome, even oppressive, many Muslim women believe that they should be wearing one, because they (i) observe others wearing one, and (ii) believe that others expect them to wear a veil, prefer them to wear a veil, and might sanction them if they did not wear one.

Such a case can be considered as an example of pluralistic ignorance, where people regard their own reasons for action differently from others' and mistakenly assume that other people's compliance with the norm results from their valuation of what the norm stands for. In the absence of transparent communication about the issue, high rates of compliance are taken as additional empirical evidence for the genuine intentions of others, and pluralistic ignorance functions as a self-fulfilling prophecy stabilizing the norm-based behavior.

In such situations, individual-level nudges or boosts are expected to be of limited value. Interventions on pluralistic ignorance must solve a collective action problem: Where strong normative expectations are in play (e.g., child marriage, female genital mutilation, and avoiding breastfeeding), educating or incentivizing people one by one is not likely to succeed. Individual beliefs and behavior might already be quite rational, given the harmful logic of the situation: No one wants be the first person to behave differently and be subject to sanctioning. Because the behavior is rooted in conditional preferences, it seems that to replace one social norm with another requires that the behavior of a large part of the population, or at least a group of trendsetters (depending on the heterogeneity and distribution of preference for conformity), must be altered collectively at once.

To deal with concrete instances of such problems, Bic-

\footnotetext{
${ }^{3}$ Imposition of quotas changes the choice set and is therefore not a soft intervention as such.
} 
chieri and her coauthors have suggested interventions that can generally be called norm design. For example, assembling a whole community to deliberate on an issue and eventually eliciting simultaneous public behavior-related pledges from a large proportion of them can influence normative attitudes and at the same time create an empirically founded belief that the other members also share the same belief and act accordingly. Such an intervention on conditional preferences can be understood as altering an old norm or as creating a new one.

One can imagine this approach being applied to the problem of overfishing. If some respected and successful fishermen could be persuaded to explain the need for reducing the catch, and personally commit to doing so, the desired change in collective behavior may well occur. Targeting the normative expectations towards free-riding in the subway might also be more effective than changing incentives (imposing higher fines and increasing inspections).

The examples of this section suggest that sometimes soft interventions targeted at formal institutions or social norms might be more effective for improving social welfare than the individual-level approaches of nudge or boost. It should be noted that the required knowledge of the relevant institutions or norms may not always be available to policy makers. Moreover, norm modification requires that a normative community exists in the first place.

\section{Conditions under which nudge, boost, and design can improve social welfare}

In this section we hypothesize conditions under which nudge, boost, and design can improve collective outcomes in meso level problems, based on the examples and literature discussed above. These conditions are presented as a springboard for more formal analyses and for better integration of a dispersed empirical literature. Table 1 organizes the provisional conditions by four aspects of meso level problems ${ }^{4}$.

\section{Preferences of individuals}

The interventions discussed in Thaler and Sunstein (2008) mostly describe situations where the true preferences of the nudgees are assumed to be relatively homogeneous and known to the nudger. This assumption seems reasonable for some problems, such as avoiding traffic accidents, but less clear for others, such as increasing saving or even physical exercise. In the latter cases, the one-size-fits-all approach of nudge faces serious challenges, as the nudge might not respect everyone's preferences. As a further challenge to nudging, uncovering people's "true system II" preferences can often be prohibitively hard (Rebonato 2012).

Since boost is targeted at competences, it does not require knowledge of preferences. Boosts should just improve each

\footnotetext{
${ }^{4}$ In Table 1, we use the term "social welfare function" (SWF) to denote the mapping from individual to social welfare. Individual welfare may or may not be fully determined by individual preferences. We do not take any normative stance toward the possible redistributive properties of the SWF and simply ignore the problem of interpersonal comparisons of utility.
}

person's ability to achieve his or her respective goals, no matter what they are.

Finally, the designer of a mechanism needs to make sure that people with radically different goals from those advanced by the institution do not engage with that institution. But this is not an unreasonable restriction. For example, why would people not committed to organ donation sign up for it? A more important restriction is that, for norm design, people's conditional preferences must be known.

\section{Form of SWF}

Nudge, boost, and design all have to take into account the exact way in which the fulfillment of individual preferences leads to collective outcomes, and which collective outcomes are attainable. These approaches could also be implemented without knowing the SWF, but then an increase in social welfare cannot be guaranteed. This is a well-established principle of design, but a central message of the present article is that it also holds for nudge and boost. As examples in the previous sections illustrate, unlike well-planned design, nudge and boost cannot handle collective action problems where robust improvements are attained only if everyone, or at least most people, act simultaneously. Nor are they alone sufficient for frequency-dependent situations where individual effects depend on how many others are subject to the intervention.

\section{Modularity of target behavior}

Consider a fictitious intervention aimed at increasing the entrepreneurship of business students by influencing their risk attitudes, but after which an increase in road accidents involving these students is observed. The desirability of a nudge often depends on its neutrality beyond the intended domain of the intervention. This can be guaranteed only if the intended behavior is suitably modular in the sense that the targeted psychological factors do not overlap with processes underlying other behaviors in nontrivial ways. To ensure the predictability of intervention outcomes, the same condition should also hold for the competence a boost intends to improve. The modularity of boosts can vary dramatically: Some simple and fast decision trees (Gigerenzer et al. 2011) are tailored to specific decision tasks and information sets, whereas improving risk and statistical literacy affects a wide range of behaviors. The corresponding challenge for design is to avoid the crowding out of intrinsic motivation, as in the erosion of civic virtues by explicit monetary incentives (Ostrom 2000).

\section{Engagement of individuals}

Nudges rely on robust behavioral reactions (often due to psychological biases) to changes in choice architecture. Hence, nudges do not require the motivation to learn and improve one's own lot. Boost, on the other hand, does require, sometimes unrealistically, that people are motivated to improve their decision competencies. Mechanism design proceeds on the assumption of self-interested agents and does not appear to require any additional motivations, whereas norm-based interventions require that a norm-seeking community exists. 
Table 1. Conditions under which nudge, boost and design can reliably improve collective outcomes

\begin{tabular}{llll}
\hline $\begin{array}{l}\text { Aspect of meso } \\
\text { problems }\end{array}$ & Intervention & Boost & Design \\
\cline { 2 - 4 } & Nudge & $\begin{array}{l}\text { No constraints on } \\
\text { preferences }\end{array}$ & $\begin{array}{l}\text { (For norm design): Known } \\
\text { conditional preferences }\end{array}$ \\
\hline $\begin{array}{l}\text { Preferences of } \\
\text { individuals }\end{array}$ & $\begin{array}{l}\text { Known and } \\
\text { homogeneous }\end{array}$ & $\begin{array}{l}\text { No collective action } \\
\text { problems and no } \\
\text { frequency dependence }\end{array}$ & Must be known \\
\hline $\begin{array}{l}\text { Modularity of } \\
\text { target behavior }\end{array}$ & $\begin{array}{l}\text { Intended behavior is } \\
\text { modular }\end{array}$ & Depends on the target & No crowding out effects \\
\hline $\begin{array}{l}\text { Engagement of } \\
\text { individuals }\end{array}$ & Not necessary & $\begin{array}{l}\text { Motivation to } \\
\text { improve competences }\end{array}$ & $\begin{array}{l}\text { (For mechanism design): self-interest; } \\
\text { (for norm design): existence of a } \\
\text { normative community }\end{array}$ \\
\hline
\end{tabular}

\section{Conclusion}

Nudging has been, by far, the most influential approach to soft interventions. One likely reason for its popularity among economists is the conceptual compatibility of the theoretical basis of nudging and economics. In particular, the language of expected utility maximization provides a smooth disciplinary interface between the psychology of decision-making and economics. Prospect theory, one of the conceptual foundations of nudging, is still utility maximization, albeit with modified probabilities and shapes of utility functions (Katsikopoulos, 2014; Friedman et al., 2014). This convenient interface, however, has also upheld the assumption that correcting deviations from neoclassical rationality at the individual level will automatically lead to improved collective outcomes.

Boost has not yet similarly caught on with economists. This could well be because its conceptual basis, the fast-andfrugal-heuristics research program, does not offer anything resembling utility maximization that could be neatly plugged into the extant structure of economic theory. Instead, it is based on concepts such as aspiration levels, ordinal comparisons, and lexicographic orders, originating in the work of Herbert Simon. Despite the theoretical and empirical successes of fast and frugal heuristics (see e.g., Katsikopoulos and Gigerenzer, 2008), the faith of most behavioral economists in prospect theory remains unshaken.

There is still a lack of empirical and theoretical research the effectiveness conditions of behavioral policy interventions (see Madrian, 2014, p. 683). We have argued that the individual-centered nudge and boost interventions cannot always reliably improve well-being at the collective level, and that design interventions can often be more appropriate for meso-level problems. The conditions of effectiveness we presented in the previous section are provisional observations about the relevant aspects of both (i) the psychology of the targeted behavior and (ii) the structure of the social situation.

Obviously, there need not be an exclusive choice between nudge, boost and design. Effective interventions should rely on insights from all three paradigms to provide advice on how groups of people reason, make decisions, and how this ultimately gives rise to meso-level outcomes. This requires genuine dialogue between various fields in the behavioral and social sciences. Such dialogue needs to extend beyond the usual approach of plugging, for example, prospect theory, into the maximization toolbox. Additionally, the promising work on group decision making and fast-and-frugal heuristics (Hertwig, Hoffrage, and the ABC Research Group, 2013) seems as yet not to be developed enough to provide guidance on regulating systems such as markets and organizations. Much more remains to be done and we hope that this article stimulates more effort in this direction.

\section{Acknowledgments}

We would like to acknowledge the generous support of the Berlin Institute for Advanced Study (Wissenschaftskolleg zu Berlin), which financed the 13th Blankensee Colloquium on "Nudge vs. Educate: Comparing Two Approaches to Policy in Terms of their Modeling Strategies", held on June 3-6, 2014, during which this work was initiated. Samuli Reijula's and Jaakko Kuorikoski's research was funded by the Academy of Finland.

We thank Shabnam Mousavi, Gerd Gigerenzer, Ralph Hertwig, Michiru Nagatsu, and the participants of the TINT seminar at the University of Helsinki for useful feedback on earlier versions of the manuscript.

\section{References}

Becker, Gary S. (1962). "Investment in human capital: A theoretical analysis". Journal of Political Economy 70: 9-49.

Ben-Porath, Elchanan, and Aviad Heifetz (2011). "Common knowledge of rationality and market clearing in 
economies with asymmetric information". Journal of Economic Theory 146: 2608-26.

Bhargava, Saurabh and George Loewenstein (2015). "Behavioral economics and public policy 102: Beyond nudging". American Economic Review: Papers \& Proceedings 105(5): 396-401.

Bicchieri, Cristina (2006). The grammar of society: The nature and dynamics of social norms. Cambridge University Press.

Bicchieri, Cristina (2016). Norms in the wild: How to diagnose, measure and change social norms. Oxford University Press.

Bond, Michael (2009). "Risk school". Nature 46: 1189-92.

Camerer, Colin F. (1992). "The rationality of prices and volume in experimental markets". Organizational Behavior and Human Decision Processes 51: 237-72.

Chetty, Raj (2015). "Behavioral economics and public policy: A pragmatic perspective". American Economic Review: Papers \& Proceedings 105(5): 1-33.

Cialdini, Robert, B. Raymond, R. Reno, and Carl A. Kallgren (1990). "A focus theory of normative conduct: Recycling the concept of norms to reduce littering in public places". Journal of Personality and Social Psychology 58: 1015-26.

Friedman, Daniel R., Mark Isaac, Duncan James, and Shyam Sunder (2014). Risky curves: On the empirical failure of expected utility. Routledge.

Gigerenzer, Gerd (2007). Gut feelings: The intelligence of the unconscious. Penguin.

Gigerenzer, Gerd (2015). "On the supposed evidence for libertarian paternalism”. Review of Philosophical Psychology 6: 361-383.

Gigerenzer, Gerd, and J. A. Muir Gray (eds.) (2011). Better doctors, better patients, better decisions. MIT Press.

Gigerenzer, Gerd, Ralph Hertwig, and Thorsten Pachur (eds.) (2011). Heuristics: The foundations of adaptive behavior. Oxford University Press.

Gode, Dhanajay K., and Shyam Sunder (1993). "Allocative efficiency of markets with zero intelligence traders: Market as a partial substitute for individual rationality". Journal of Political Economy 101: 119-37.

Grüne-Yanoff, T., and Ralph Hertwig (2016). "Nudge versus boost: How coherent are policy and theory?". Minds and Machines 26 (1-2): 149-183.

Hertwig, Ralph and Till Grüne-Yanoff (2017). "Nudging and boosting: Steering or empowering good decisions". Perspectives on Psychological Science 12(6), 973-986.
Hertwig, Ralph, Ulrich Hoffrage, and the ABC Research Group, (2013). Simple heuristics in a social world. Oxford University Press.

Hukkinen, Janne (2016). "Addressing the practical and ethical issues of nudging in environmental policy". Environmental Values 25, 329-351.

Johnson, Eric, Suzanne Shu, Benedict Dellaert, Craig Fox, Daniel G. Goldstein, Gerald Häubl, Richard P. Larrick, John W. Payne, Ellen Peters, David Schkade, Brian Wansink, Elke U. Weber. (2012). "Beyond nudges: Tools of a choice architecture". Marketing Letters, 23: 487-504.

Kahneman, Daniel, and Amos Tversky (2000). Choices, values and frames. Cambridge University Press.

Kahneman, Daniel, Paul Slovic, and Amos Tversky (1982). Judgment under uncertainty: Heuristics and biases. Cambridge University Press.

Katsikopoulos, Konstantinos V. (2014). "Bounded rationality: The two cultures". Journal of Economic Methodology 21: 361-74.

Katsikopoulos, Konstantinos V., and Gerd Gigerenzer (2008). "One-reason decision-making: Modeling violations of expected utility theory". Journal of Risk and Uncertainty 37: 35-56.

Mackie, Gerry (1996). "Ending footbinding and infibulation: A convention account". American Sociological Review 62. 999-1017.

Madrian, Brigitte, C. (2014). "Applying insights from behavioral economics to policy design". Annual Review of Economics 6: 663-88.

Nagatsu, Michiru (2015). "Social nudges: Their mechanisms and justification". Review of Philosophy and Psychology 6: 481-494.

Ostrom, Elinor (2000). “Crowding out citizenship". Scandinavian Political Studies 23: 3-16.

Rebonato, Riccardo (2012). Taking liberties. Palgrave Macmillan.

Roth, Alvin (1984). "The evolution of the labor market for medical interns and residents: A case study in game theory". Journal of Political Economy 92: 991-1016.

Roth, Alvin (2008). "What have we learned from market design?" Hahn lecture. Economic Journal 118: 285310 .

Simsek, Alp (2013). "Financial innovation and portfolio risks". The American Economic Review 103(3): 398401. 
Smith, Vernon L. (1962). "An experimental study of competitive market behavior". Journal of Political Economy 70: 111-37.

Sunstein, Cass R. (2015). "Nudges, navigability, and abstraction: A reply to critics". Review of Philosophy and Psychology 6(3), Special Issue on Nudges.

Thaler, Richard H., and Cass R. Sunstein (2003). "Libertarian paternalism". The American Economic Review 93, 175-179.

Thaler, Richard H., and Cass R. Sunstein (2008). Nudge: Improving decisions about health, wealth, and happiness. Yale University Press.

United Nations, Food and Agriculture Organization (2014). "The state of the world fisheries and aquaculture: Opportunities and challenges". URL: fao.org/3/a-i3720e.pdf 